\title{
Symptom Frequencies and Correlations with Temperature Variations in Suspected Cases of Neuroleptic Malignant Syndrome (NMS)
}

\author{
Varadaraj R. Velamoor, Stephan C. Mann, Michel A. Woodbury, and Zack Z. Cernovsky
}

\section{ABSTRACT}

Background: The incidence of NMS is rare. Relative frequencies of symptoms that are most valuable in making a diagnosis of NMS can be assessed statistically only if a large sample of suspected NMS cases is available. Similarly, the relationship of such NMS symptoms to temperature (a cardinal symptom of NMS) can be meaningfully evaluated only by studying large samples.

Method: De-identified archival data on 212 suspected NMS cases were obtained from professionals across the USA and Canada or were extracted from studies published in medical journals. We recorded the symptoms frequencies. The patients' temperature ranged from $37.2^{\circ} \mathrm{C}$ to $43.0^{\circ} \mathrm{C}$, with the mean at $39.5^{\circ}(\mathrm{SD}=1.3)$. All cases were caused by older first-generation antipsychotics (FGAs). We evaluated the frequencies of symptoms reported in these cases. These included symptoms in the realm of mental status, rigidity, and autonomic symptoms. We calculated the frequency of abnormal blood pressure, respiration and heart rate, symptoms such as Dysarthria, Dysphagia, Rigidity, Focal Dystonia, Waxy Flexibility, Myoclonus, Masked Facies, Bradykinesia, Akinesia, Cogwheeling, Stupor, Coma, Obtundation, Mutism, Decrease in Consciousness, Disorientation, Diaphoresis, Sialorrhea, and Seizures. We also calculated their correlations with temperature elevations, the most spectacular symptom of this dangerous syndrome.

Results: The highest symptom frequencies (those $>10 \%$ ) were found for Rigidity $(91.0 \%$ of patients), Autonomic Instability (66.5\%), Diaphoresis (45.8\%), Mutism (34.4\%), Tremor (31.6\%), Stupor (20.3\%), Confusion (15.6\%), Incontinence (15.6\%), Sialorrhea (14.6\%), Coma (13.2\%), and Dysphagia (11.3\%). Other symptoms were too rare within the sample of the 212 suspected NMS cases to calculate the statistical significances of their relationships to temperature. The only significant correlations found of temperature were to increased heart rate and to the severe cases of coma.

Discussion and Conclusion: Besides the elevated temperature, the most frequently reported symptoms in this sample of suspected NMS caused by FGAs were Rigidity, Autonomic Instability, Diaphoresis, Mutism, and Tremor. Higher temperature was associated with tachycardia as well as profound impairment of consciousness or coma. Reviews and database studies of second generation antipsychotics (SGAs), also referred to as atypical antipsychotics, suggest a lower incidence of NMS and milder severity of symptoms such as hyperthermia and rigidity. It would be of clinical interest to generate similar de-identified files of archival data for suspected cases of NMS in patients treated with SGAs. Furthermore, a similar profile derived from archival data on milder or prodromal NMS cases could enhance our understanding of this syndrome from a spectrum perspective.

Keywords: Antipsychotics, NMS, rigidity, temperature.
Submitted : August 29, 2021

Published. : November 17, 2021

ISSN: 2593-8339

DOI: $10.24018 /$ ejmed.2021.3.6.1035

\section{R. Velamoor*}

Department of Psychiatry, Laurentian and Lakehead Universities, and Western University, Ontario, Canada.

(e-mail: velamoorraj@gmail.com) S. C. Mann*

Central Montgomery Behavioral Heath, Norristown, PA, USA.

(e-mail: smann1234@aol.com)

M. A. Woodbury

Department of Psychiatry, University of Puerto Rico, San Juan, Puerto Rico, USA.

(e-mail: michel.woodbury@upr.edu)

Z. Z. Cernovsky

Department of Psychiatry, Western

University, Ontario, Canada.

(e-mail: zcernovs@uwo.ca)

*Corresponding Authors

\section{INTRODUCTION}

The Neuroleptic Malignant Syndrome (NMS) as described on page 710 in the text of DSM-5[1] involves:
1) Exposure to dopamine-receptor blocker agents (antipsychotics) or during withdrawal from dopamine agonists used in Parkinson's disease, within the preceding 72 hours prior to the development of symptoms, and typically including the following: 
2) hyperthermia ( $>38.0$ Celsius) on at least 2 occasions, measured orally, and associated with profuse diaphoresis.

3) muscle rigidity usually unresponsive to antiparkinsonian agents and often associated with tremor, sialorrhea, akinesia, dystonia, trismus, myoclonus, dysarthria, dysphagia, rhabdomyolysis. Serum creatine kinase (CK) elevations at least four times the normal upper limit are common.

4) Changes in mental status with delirium or altered consciousness ranging from stupor to coma are often an early sign. The patient may appear alert but unresponsive (as in catatonic stupor).

5) Autonomic activation and instability is common as an early warning sign, with tachycardia $(25 \%$ over baseline), diaphoresis, blood pressure elevation (systolic or diastolic of at least $25 \%$ above baseline) or fluctuation (at least $20 \mathrm{mmHg}$ diastolic or $25 \mathrm{mmHg}$ systolic change within 24 hours), urinary incontinence, and pallor.

6) Tachypnea (rate of 50\% above baseline) and respiratory distress resulting from metabolic acidosis, hypermetabolism, chest wall restriction, aspiration pneumonia, or pulmonary emboli potentially leading to respiratory arrest.

7) Although several abnormal laboratory findings are common, none are specific or pathognomonic for NMS: leukocytosis, metabolic acidosis, hypoxia, decreased serum iron concentrations, elevated serum catecholamines and elevations in serum muscle enzymes, especially $\mathrm{CK}, \mathrm{LDH}$, transaminases, and aldolase. The EEG may show generalized slowing.

8) Some NMS cases develop within 24 hours of drug initiation, but most within the first week, and $96 \%$ within 30 days. Only $4 \%$ of reported cases developed NMS beyond 30 days (Caroff et al. in press[2]). Fatality rates of $10 \%$ to $20 \%$ have been reported when the disorder is not recognized. An increased risk for NMS is reported for agitated, exhausted, dehydrated, physically restrained, and iron deficient patients.

NMS has been more commonly reported with first generation high-potency drugs. The risk of NMS with longacting depot antipsychotics has been controversial, with concerns regarding increased incidence or a more prolonged course. However, a recent study found no association between depot preparations and NMS, aside from the use of older FGA depot agents [2].

NMS triggered by second generation antipsychotics (SGA) might be not only less frequent but also less clinically severe, and associated with lower mortality rates. Furthermore, it can present with an atypical symptom patterns such as with less intense extrapyramidal symptoms (EPS) or less increase in temperature [3], [4]. The atypical NMS patterns might be observed more frequently with NMS-like syndromes triggered by clozapine (less severe EPS), aripiprazole (less severe hyperthermia and autonomic symptoms), and amisulpride (less severe EPS and hyperthermia). In contrast, the "NMS induced by olanzapine, risperidone, quetiapine, paliperidone, and ziprasidone seem similar to that of 'typical' NMS triggered by first generation antipsychotics.'[3].

Individual practitioners may only have limited personal clinical experience in diagnosing and managing this disorder as NMS occurs infrequently. Evidence from database studies suggests incidence rates for NMS of $0.01 \%$ to $0.02 \%$ among individuals treated with antipsychotics [1]. This is especially worrisome for family physicians in remote underserviced areas who prescribe antipsychotic medications as they do not have easy access to psychiatrists for their patients. However, as emphasized in [5] even experienced "clinicians are often baffled by the array of hyperthermic conditions that overlap with NMS and complicate the differential diagnosis."

The DSM5 diagnosis of NMS is more pragmatic and descriptive compared to its predecessors as it facilitates the identification of typical cases of NMS. However, clinicians who treat hundreds of psychotic patients encounter NMS presentations with atypical symptom patterns that seem clinically somewhat similar, but do not necessarily meet all the criteria described in the DSM5 system [6]. It is noteworthy that [7] concluded, "hyperthermia and/or muscle rigidity may be absent or develop slowly over several days, leading to impairment or a significant delay in diagnosis and treatment. Evidence from case reports and retrospective evaluations supports a concept of atypical NMS, particularly with regard to treatment with atypical antipsychotics. However, it remains unclear whether these atypical presentations represent early or impending NMS."

Reference [8] reviewed 340 publications of NMS cases to establish the temporal sequence in the development of the 4 key NMS symptoms: mental-status changes, muscle rigidity, hyperthermia, and autonomic dysfunction. Velamoor's study determined that "Changes in either mental status or rigidity were the initial manifestations of NMS in $82.3 \%$ of cases with a single presenting sign and were significantly more likely to be observed before hyperthermia and autonomic dysfunction". Muscle rigidity leads to heat generation and represents a major contributor to hyperthermia in NMS [9].

In the present article, we have specifically focused on the frequency of symptoms as well as role of temperature in the symptom patterns of NMS, including its atypical forms. This might explain the causation of atypical cases by certain SGAs, particularly aripiprazole (NMS with less severe fever and autonomic symptoms) and amisulpride (NMS with less severe EPS and fever) [3]. As Velamoor's study determined that hyperthermia is usually a later sign in the development of the NMS [8] and since hyperthermia may be even absent or develop rather slowly over several days, [7] some cases of atypical or incipient NMS may be entirely missed and their clinical management unduly delayed. For this reason, we have intentionally included in our sample 36 patients whose temperature did not exceed $38^{\circ} \mathrm{C}$, ranging from $37.2^{\circ} \mathrm{C}$ to $38^{\circ} \mathrm{C}$, in order to detect atypical forms of NMS.

The DSM5 criteria would require oral temperature to be above $38^{\circ} \mathrm{C}$. Although this diagnostic cutoff is of pragmatic value, the following statistical considerations are consequential. There is some consensus that "thermoregulatory physiology sustains health by keeping body core temperature within a degree or two of $37^{\circ} \mathrm{C}$, which enables normal cellular function" [10]. The study by [11] suggested that, rather than the oral temperature of $37^{\circ} \mathrm{C}$, the average in normal persons is $36.8^{\circ} \mathrm{C}$. The meta-analytic study by [12] determined the average normal human temperature to be $36.57{ }^{\circ} \mathrm{C}(\mathrm{SD}=0.42)$ for oral, $35.97{ }^{\circ} \mathrm{C}(\mathrm{SD}=0.48)$ for axillary, and $36.64^{\circ} \mathrm{C} \quad(\mathrm{SD}=0.44)$ for tympanic 
measurements. If we assume normal statistical distribution of temperature measures and use the above SDs from Geneva's study, then $15.9 \%$ of individual patients might have measured oral temperature between $36.57^{\circ} \mathrm{C}$ and $36.15^{\circ} \mathrm{C}$ and another $15.9 \%$ oral temperature between $36.57{ }^{\circ} \mathrm{C}$ and $36.99{ }^{\circ} \mathrm{C}$. Similar inter-individual differences might exist around the criterion of $38{ }^{\circ} \mathrm{C}$, making this cutoff criterion less precise. The $38^{\circ}$ is perhaps only reached by some individuals and rarely by others. The latter type of patients could be diagnosed as atypical or perhaps subclinical NMS.

As implied, the correlates of temperature in NMS and atypical NMS presumably depend on the stage in the progression of the symptom pattern. In a system broadly based on a 1992 publication by [13], the stages of the progression in the syndrome can be summarized as in Table I.

TABLE I: STAGES OF PROGRESSION OF NMS

\begin{tabular}{cl}
\hline \hline Stage of NMS: & \multicolumn{1}{c}{ Symptom pattern: } \\
\hline \hline Stage 1 & Some rigidity, tremor \\
Stage 2 & Some rigidity, mutism, stupor \\
& Mild rigidity, stupor, or confusion, temperature \\
Stage 3 & $38-39^{0} \mathrm{C}$, heart rate $90-110 \mathrm{bpm}$ \\
& Moderate rigidity, stupor or confusion, \\
Stage 4 & temperature 39-40 $\mathrm{C}$, heart rate 100-130 bpm \\
& Severe rigidity, stupor or confusion, \\
& temperature 39-42 ${ }^{\circ} \mathrm{C}$, heart rate $130-150$ beats \\
Stage 5 & per minute \\
\hline \hline Note: Adapted from [13] with permission.
\end{tabular}

The symptom patterns of NMS do not necessarily progress by a linear increase of their intensity. The NMS pattern may be stage specific, reflective of the severity of the NMS. Furthermore, [13] based on their clinical experience, proposed a stage specific intervention for each stage. In 1995, [14] reviewed the literature with two case illustrations and provided data regarding early or suspected cases and offered guidelines for management and concluded that "The most rational approach to treating NMS entails a hierarchy of interventions determined by the severity and progression of symptoms." A review of NMS by [15] presented a tabular summary derived from [13] as a treatment algorithm based on "clinical presentation by illness stage and severity."

A major difficulty in diagnosing NMS is with patients who show less typical or atypical forms of the syndrome, regardless of the stage of its progression. To facilitate the diagnostic work, an extensive mapping is needed of less typical or atypical symptoms while statistically determining their frequencies. This is possible only on very large samples of suspected NMS cases, as in the present study.

In Woodbury's tabular summary, advanced NMS stages are defined mainly by levels of temperature as a key diagnostic dimension [13]. In contrast, the present study assesses via linear correlations how the level of temperature is related to the multitude of other diagnostically useful variables relevant in NMS research. Briefly, the goal of the present study is not only to study symptom frequencies, but also to examine the relationships of temperature to other NMS symptoms. If the presence of certain symptoms is specific only to high temperatures and if these symptoms are frequent enough in the NMS, then their correlations to temperature would be statistically significant.

The data in our study are based on first generation antipsychotics because they trigger NMS symptoms more frequently. The goal of the present study is to provide the data on frequencies of symptoms considered by clinicians as relevant in assessments of suspected NMS. As the next step, the study evaluates correlations of these symptoms to the level of elevated temperature, ranging from $37.2^{\circ} \mathrm{C}$ to $43.0^{\circ} \mathrm{C}$ in the sample of 212 patients.

\section{METHOD}

De-identified archival data on 212 suspected NMS cases were obtained from professionals across the USA and Canada and from studies published in medical journals. Their temperature ranged from $37.2^{\circ} \mathrm{C}$ to $43.0^{\circ} \mathrm{C}$, with the mean at $39.5^{\circ} \mathrm{C}(\mathrm{SD}=1.3)$. None of the 212 patients had temperature below normal. We included only those with known measures of temperature. Only 36 of the 212 patients, i.e., $17.0 \%$, had temperature not exceeding $38^{\circ} \mathrm{C}$.

Some of the data was provided over the phone by busy emergency clinicians: the information on age of the patient was missing for 9 persons and gender remained unknown for 7. Among the remaining patients, there were 75 women and 130 men. The age ranged from 1 to 90 years with the mean at 41.2 years $(\mathrm{SD}=18.1) ; 4.9 \%$ of the sample was younger than the age of 18 years and $5.4 \%$ were older than 70 years. The sample partly overlaps with the one used in the 2019 study by Velamoor and Cernovsky on NMS patterns specific to gender and age groups [16].

All patients were on the old FGAs prior to developing the NMS, however, the specific name of the old antipsychotic was available only for 138 of the 212 patients. The most frequently reported was haloperidol (55.1\%), chlorpromazine (15.6\%), fluphenazine $(7.5 \%)$, and trifluoperazine $(5.2 \%)$, either alone or in combination with other older antipsychotics. None of these patients were on SGAs.

In addition to the first generation antipsychotics, some patients were on antiparkinsonian medication (31.9\%), antidepressants $(8 \%)$, benzodiazepines $(8 \%)$, or mood stabilizers such as lithium or carbamazepine (10.9\%).

Our data file included the following variables: age, gender, systolic and diastolic blood pressure, pulse, respiration rate, and the following behavioral symptoms: Dysarthria, Dysphagia, Rigidity, Focal Dystonia, Waxy Flexibility, Myoclonus, Seizures, Masked Facies, Bradykinesia, Akinesia, Cogwheeling, Stupor, Coma, Obtundation, Mutism, Decrease in Consciousness, Disorientation, Drowsiness, Incoherence, Delirium, Withdrawal, Catalepsy, Mobility, Alertness, Agitation, Confusion, Autonomic Instability, Diaphoresis, Sialorrhea, Incontinence, and Tremor. The importance of these variables in NMS research has been discussed in various publications [2], [4], [7], [17]. One of the problems with such lists of variables is that some of them partly overlap conceptually, for example, Alertness with Decrease of Consciousness, or Drowsiness.

Laboratory measures of $\mathrm{CK}, \mathrm{WBC}$, and metabolic acidosis or hypoxia on blood-gas analysis were available for too few patients to provide representative data. 


\section{RESULtS}

\section{A. Symptom Frequencies in this Sample of Suspected NMS cases}

As noted, the temperature of the 212 patients with suspected NMS ranged from $37.2^{\circ} \mathrm{C}$ to $43.0^{\circ} \mathrm{C}$, with the mean at $39.5{ }^{\circ} \mathrm{C}(\mathrm{SD}=1.3)$ : none of the 212 patients had a temperature below normal. Only $17.0 \%$ of patients had temperature not exceeding $38.0^{\circ} \mathrm{C}$.

The distributions of low, normal, and elevated vital signs are reported in Table II. Some of the busy emergency physicians reported only cases with abnormal vital signs, rather than providing vital signs for all suspected NMS cases.

However, it is of interest that no cases of bradycardia (pulse $<60$ beats per minute) were reported. In contrast, reports of tachycardia (pulse $>100$ beats per minute) were very common.

TABLE II: REPORTED VITAL SIGNS IN PATIENTS WITH SUSPECTED NMS

\begin{tabular}{|c|c|c|c|c|}
\hline & Range & Low & Normal & Elevated \\
\hline Pulse $(\mathrm{N}=106)$ & $\begin{array}{l}80 \text { to } \\
220\end{array}$ & $0 \%$ & $10.6 \%$ & $89.4 \%$ \\
\hline $\begin{array}{l}\text { Systolic blood pressure } \\
\qquad(\mathrm{N}=106)\end{array}$ & $\begin{array}{l}40 \text { to } \\
210\end{array}$ & $11.3 \%$ & $8.5 \%$ & $80.2 \%$ \\
\hline $\begin{array}{l}\text { Diastolic blood pressure } \\
\qquad(\mathrm{N}=99)\end{array}$ & $\begin{array}{c}30 \text { to } \\
130\end{array}$ & $10.1 \%$ & $9.1 \%$ & $76.8 \%$ \\
\hline Respiration rate $(\mathrm{N}=23)$ & $\begin{array}{l}20 \text { to } \\
80\end{array}$ & $0 \%$ & $0 \%$ & $100 \%$ \\
\hline
\end{tabular}

TABLE III: FREQUENCIES OF CLINICAL FEATURES

\begin{tabular}{|c|c|}
\hline Symptom: & Frequency $(\%)$ \\
\hline Rigidity & $91.0 \%$ \\
\hline Tachycardia $(\mathrm{N}=106)$ & $89.4 \%$ \\
\hline $\begin{array}{l}\text { Systolic Blood Pressure of or above } 120 \mathrm{~mm} \\
\qquad \operatorname{Hg}(\mathrm{N}=106)\end{array}$ & $80.2 \%$ \\
\hline $\begin{array}{l}\text { Diastolic Blood Pressure of or above } 80 \mathrm{~mm} \mathrm{Hg} \\
\qquad(\mathrm{N}=99)\end{array}$ & $76.8 \%$ \\
\hline Autonomic Instability & $66.5 \%$ \\
\hline Diaphoresis & $45.8 \%$ \\
\hline Mutism & $34.4 \%$ \\
\hline Tremor & $31.6 \%$ \\
\hline Stupor & $20.3 \%$ \\
\hline Confusion & $15.6 \%$ \\
\hline Incontinence & $15.6 \%$ \\
\hline Sialorrhea & $14.6 \%$ \\
\hline Coma & $13.2 \%$ \\
\hline $\begin{array}{l}\text { Systolic Blood Pressure below 90mm Hg } \\
\qquad(\mathrm{N}=106)\end{array}$ & $11.3 \%$ \\
\hline $\begin{array}{l}\text { Diastolic Blood Pressure below 60mm Hg } \\
\qquad(\mathrm{N}=106)\end{array}$ & $10.1 \%$ \\
\hline Dysphagia & $11.3 \%$ \\
\hline Dysarthria & $7.1 \%$ \\
\hline Agitation & $8.0 \%$ \\
\hline Catalepsy & $7.5 \%$ \\
\hline Delirium & $6.1 \%$ \\
\hline Cogwheeling & $3.8 \%$ \\
\hline Akinesia & $3.3 \%$ \\
\hline Drowsiness & $2.8 \%$ \\
\hline Masked Facies & $2.8 \%$ \\
\hline Seizures & $2.4 \%$ \\
\hline Bradykinesia & $1.9 \%$ \\
\hline Focal Dystonia & $1.9 \%$ \\
\hline Withdrawal & $1.9 \%$ \\
\hline Waxy Flexibility & $1.4 \%$ \\
\hline Decrease in Consciousness & $1.4 \%$ \\
\hline Alertness & $1.4 \%$ \\
\hline Obtundation & $0.9 \%$ \\
\hline Disorientation & $0.9 \%$ \\
\hline Incoherence & $0.9 \%$ \\
\hline Mobility & $0.5 \%$ \\
\hline Myoclonus & $0.5 \%$ \\
\hline
\end{tabular}

Legend: The overall number of patients was 212, except for measures of pulse $(\mathrm{N}=106)$, systolic blood pressure $(\mathrm{N}=106)$, and diastolic blood pressure $(\mathrm{N}=99)$.
Low blood pressure (below 90/60 mm $\mathrm{Hg}$ ) was noted rarely (less than in 12\%) and the same was true of reports of blood pressure within the normal range (i.e., below 120/90 mm Hg). The measures of pulse and systolic blood pressure were reported for 106 patients only and diastolic blood pressure for only 99 patients. In many of the other cases, rather than being recorded as high or low, the blood pressure and/or pulse were fluctuating in a manner indicating autonomic instability and this was then reported as “autonomic instability," see Table III.

The average systolic blood pressure was 142.3 ( $\mathrm{SD}=37.2)$ and average diastolic blood pressure was 89.8 ( $\mathrm{SD}=22.9)$.

Unfortunately, respiration rate was recorded only for 23 patients: for this reason, the data on respiration rate are not included in the Table III. The clinicians presumably recorded respiration rate only for those with obvious tachypnea. The respiration rate ranged from 20 to 80 per minute, with the mean at $38.9(\mathrm{SD}=14.8)$. There were no reports of very slow respiration. Only 4 patients had respiration rate below 25 (one of these patients had breathing rate of 20 and 3 patients the rate of 24 per minute).

The frequencies of the various NMS symptoms are summarized in Table III. When reading the tabular data, it is important to recall that some of these variables represent partly overlapping concepts, i.e., they are not conceptually independent.

Muscular rigidity was absent only in 19 of 212 patients. Among these 19 , the average temperature $\left(39.5^{\circ} \mathrm{C}, \mathrm{SD}=1.3\right)$ was similar to the remaining patients and ranged from $37.2^{\circ} \mathrm{C}$ to $41.5{ }^{\circ} \mathrm{C}$. Only 3 of these 19 patients had temperatures below $38{ }^{\circ} \mathrm{C}$; their temperatures were $37.2{ }^{\circ} \mathrm{C}, 37.8{ }^{\circ} \mathrm{C}$ and $37.9^{\circ} \mathrm{C}$ i.e., all 3 were within the upper limit of the normal range, or may also be considered by some clinicians as mildly elevated depending on the criteria used.

\section{B. Correlations of Temperature to the Individual Symptoms}

The calculation of correlations is meaningful only if there are at least 10 patients with the symptom present, i.e., at least $4.7 \%$ of the 212. As shown in Table III, this is the case with symptoms ranging from cogwheeling (present only in $3.8 \%$, i.e., in 8 patients) to myoclonus (present only in $0.5 \%$, i.e., in one patient). Such small numbers of patients do not provide generalizable information about the impact of the particular symptom on the level of temperature. For example, a significant inverse correlation was found in this study of temperature to the symptom of waxy flexibility $(r=-0.18$, $\mathrm{p}=0.008$, 2-tailed), however, since the symptom was present in only 3 patients, they do not represent a statistically sufficient evidence to interpret the relationships between waxy flexibility and temperature in suspected NMS cases.

The correlation is also less meaningful if calculated based on data in which less than 10 patients from the sample do not have the symptom, i.e., when the incidence of the particular symptom exceeds $95.3 \%$ in this sample of 212 patients. If the large group of patients with the particular symptom are compared only to a few patients $(\mathrm{N}<10)$ without the symptom, such statistical comparison would not provide generalizable information about the impact of presence versus absence of the particular symptom on the level of temperature. However, 
none of the symptoms listed in Table III reached the very high frequency, with less than 10 patients without the symptom.

The following meaningful correlations were found. Higher level of temperature was associated with tachycardia $(\mathrm{r}=0.28$, $\mathrm{p}=0.001$, 2-tailed) and with more cases of coma $(\mathrm{r}=0.18$, $\mathrm{p}=0.001$, 2-tailed).

None of the patients in this study had abnormally slow pulse: the pulse ranged from 80 to 220 beats per minute, with the average at $131.4, \mathrm{SD}=24.8$.

\section{Other Statistical Challenges}

Special problems were encountered while calculating the correlations to systolic and diastolic blood pressure in this sample of patients. Some patients had abnormally low, some had normal values, and some abnormally elevated values on these variables. The relationships of temperature to blood pressure needed to be treated as (at least potentially) curvilinear because both abnormally low and the abnormally high values are pathological phenomena. In the present study, the problem has been approached by creating, for each of these vital sign variables, two dichotomies: one variable that only included normal and pathologically high values and another including only abnormally low to normal values. Thus, for the systolic blood pressure (SBP), one variable was created to examine the relationship of temperature to a range of normal to elevated SBP by excluding cases of SBP < $90 \mathrm{~mm} \mathrm{Hg}$ : this allows examination of whether elevated temperature in NMS is statistically associated with elevated SBP. Similarly, a second variable was created to examine the relationship of temperature to a range of pathologically low to normal SBP by excluding cases of SBP $>119 \mathrm{~mm} \mathrm{Hg}$.

For the diastolic blood pressure (DBP), one variable was created to examine the relationship of temperature to a range of normal to elevated DBP by excluding cases of DBP < $60 \mathrm{~mm} \mathrm{Hg}$. Similarly, a second variable was created to examine the relationship of temperature to a range from pathologically low to normal DBP by excluding cases of DBP $>119 \mathrm{~mm} \mathrm{Hg}$. Temperature measure were not significantly correlated ( $p>0.05,2$-tailed) to high SBP when pathologically low measures of $<90 \mathrm{~mm} \mathrm{Hg}$ were excluded $(\mathrm{r}=-0.07)$ and to high DBP when pathologically low measures of $<60 \mathrm{~mm} \mathrm{Hg}$ were excluded $(\mathrm{r}=-0.05)$.

Temperature measure were not significantly correlated ( $>0.05,2$-tailed) to low SBP when pathologically high measures of $>119 \mathrm{~mm} \mathrm{Hg}$ were excluded $(\mathrm{r}=-0.24, \mathrm{p}=0.305$, 2-tailed) and to low DBP when pathologically high measures of $>79 \mathrm{~mm} \mathrm{Hg}$ were excluded ( $\mathrm{r}=-0.38, \mathrm{p}=0.072$, 2-tailed).

As mentioned, the data on tachypnea consisted only of rates 20 or above, with the measures reported for only 23 patients. The correlation of these measures of respiration rate to temperature was not statistically significant and was equal to zero.

\section{DISCUSSION}

The strength of the present study is in providing frequency data on a large and diverse assortment of symptoms considered by clinicians as potentially relevant for NMS detection and investigations. Each of the 212 patients was presumably at a different or particular stage of the NMS. Since the symptom pattern of the NMS is likely to change as the syndrome progresses, the results in our Table III could be somewhat different in samples of patients in early stages of NMS than in patients in an advanced stage with higher temperature, see Table IV.

\begin{tabular}{|c|c|c|}
\hline \multirow[b]{2}{*}{ Symptom } & \multicolumn{2}{|c|}{ Frequency of Symptoms (\%) } \\
\hline & $\begin{array}{c}\text { Temperature } \\
<38.5^{0} \mathrm{C}(\mathrm{N}=55) \\
\end{array}$ & $\begin{array}{c}\text { Temperature } \\
>40.0^{\circ} \mathrm{C}(\mathrm{N}=55) \\
\end{array}$ \\
\hline Rigidity & $89.1 \%$ & $87.3 \%$ \\
\hline $\begin{array}{c}\text { Tachycardia ( }>100 \text { beats } \\
\text { per minute) }\end{array}$ & $83.3 \%(\mathrm{~N}=36)$ & $96.8 \%(\mathrm{~N}=31)$ \\
\hline $\begin{array}{l}\text { Systolic Blood Pressure of } \\
\text { or above } 120 \mathrm{~mm} \mathrm{Hg}\end{array}$ & $90.0 \%(\mathrm{~N}=30)$ & $50.0 \%(\mathrm{~N}=26)$ \\
\hline $\begin{array}{l}\text { Diastolic Blood Pressure of } \\
\text { or above } 80 \mathrm{~mm} \mathrm{Hg}\end{array}$ & $88.9 \%(\mathrm{~N}=27)$ & $50.0 \%(\mathrm{~N}=26)$ \\
\hline Autonomic Instability & $54.5 \%$ & $65.5 \%$ \\
\hline Diaphoresis & $43.6 \%$ & $36.4 \%$ \\
\hline Mutism & $38.2 \%$ & $21.8 \%$ \\
\hline Tremor & $27.3 \%$ & $34.5 \%$ \\
\hline Stupor & $12.7 \%$ & $21.8 \%$ \\
\hline Confusion & $21.8 \%$ & $9.1 \%$ \\
\hline Incontinence & $16.4 \%$ & $9.1 \%$ \\
\hline Sialorrhea & $18.2 \%$ & $3.6 \%$ \\
\hline Coma & $9.1 \%$ & $20.0 \%$ \\
\hline $\begin{array}{l}\text { Systolic Blood Pressure } \\
\text { below } 90 \mathrm{~mm} \mathrm{Hg}\end{array}$ & $3.3 \%(\mathrm{~N}=30)$ & $34.6 \%(\mathrm{~N}=26)$ \\
\hline $\begin{array}{l}\text { Diastolic Blood Pressure } \\
\text { below } 60 \mathrm{~mm} \mathrm{Hg}\end{array}$ & $0.0 \%(\mathrm{~N}=27)$ & $33.3 \%(\mathrm{~N}=26)$ \\
\hline Dysphagia & $7.3 \%$ & $1.8 \%$ \\
\hline Dysarthria & $3.6 \%$ & $12.7 \%$ \\
\hline Agitation & $9.1 \%$ & $10.9 \%$ \\
\hline Catalepsy & $12.7 \%$ & $5.5 \%$ \\
\hline Delirium & $12.7 \%$ & $5.5 \%$ \\
\hline Cogwheeling & $7.3 \%$ & $5.5 \%$ \\
\hline Akinesia & $7.3 \%$ & $0.0 \%$ \\
\hline Drowsiness & $1.8 \%$ & $3.6 \%$ \\
\hline Masked Facies & $7.3 \%$ & $0.0 \%$ \\
\hline Seizures & $3.6 \%$ & $3.6 \%$ \\
\hline Bradykinesia & $5.5 \%$ & $0.0 \%$ \\
\hline Focal Dystonia & $5.5 \%$ & $1.8 \%$ \\
\hline Withdrawal & $1.8 \%$ & $0.0 \%$ \\
\hline Waxy Flexibility & $5.5 \%$ & $0.0 \%$ \\
\hline Decrease in Consciousness & $1.8 \%$ & $1.8 \%$ \\
\hline Alertness & $1.8 \%$ & $0.0 \%$ \\
\hline Obtundation & $0.0 \%$ & $1.8 \%$ \\
\hline Disorientation & $0.0 \%$ & $0.0 \%$ \\
\hline Incoherence & $1.8 \%$ & $1.8 \%$ \\
\hline Mobility & $1.8 \%$ & $0.0 \%$ \\
\hline Myoclonus & $0.0 \%$ & $1.8 \%$ \\
\hline
\end{tabular}

Temperature is often associated with the severity of NMS. It also triggers a host of other cascading NMS symptoms such as changes in the level of consciousness and various physiological changes potentially culminating in cardiac arrest. For this reason, it is perplexing that only two significant correlations of temperature to other NMS symptoms were found; those involving the tachycardia and coma (loss of consciousness).

The data can be also presented in a clinically more visual manner in a table that lists symptoms occurring in patients with temperature $<38.5{ }^{\circ} \mathrm{C}$ (55 patients of the 212 , i.e., $25.9 \%$ ) compared to patients with temperature $>40.0^{\circ} \mathrm{C}(55$ patients of 212 , i.e., $25.9 \%$ ), see Table IV. This facilitates a spectrum approach in the understanding of this condition.

The Table IV contrasts two extreme groups, defined by the opposite poles of the dimension delineated by levels of temperature.

There are only very few differences in symptoms between the two groups of patients in Table IV, that amount to $25.0 \%$ 
or more, i.e., between those having NMS with lower temperature and those with a higher temperature. All these large differences involve systolic and diastolic blood pressure. Elevation of blood pressure was more common in NMS cases with a lower temperature and conversely low blood pressure was encountered more often in those with a higher temperature. However, these differences perhaps reflect the attention of clinicians on potential signs of NMS. Thus, for instance, if the temperature was not highly elevated and remained below $38.5^{\circ} \mathrm{C}$, the clinicians might have been alarmed by the presence of elevated systolic or diastolic blood pressure: this contrasts with the hyperthermic patients $\left(>40^{\circ} \mathrm{C}\right)$ in whom the hyperthermia per se would already be a compelling reason to consider NMS, even if the blood pressure was not elevated. Such clinical and methodological considerations point to the difficulties involved in interpretation of data displayed in the Table IV.

The higher frequency of abnormally low blood pressure in the hyperthermic group (the right column of Table IV) is noteworthy. In clinical general medicine, hyperthermia associated with low blood pressure may be indicative of dehydration, infection, inflammation and even sepsis, i.e., of debilitating conditions conducive to autonomic dysregulation. In our sample of suspected NMS patients, the low blood pressure may be consistent with the severity of NMS, similarly as the hyperthermia and rigidity.

Another problem with interpretation of Table IV is of a semantic nature. A clinician describing the patient may label him as drowsy (and not as showing decreased level of consciousness). Another clinician rating the same patient may describe him as showing a decreased level of consciousness (and not as drowsy). A third clinician may possibly describe the same patient as obtunded (and avoid the labels of drowsiness or of decrease of consciousness). Still, each term describes a change in mental status in the same path along the same dimension. Table IV contains several verbal concepts that partly overlap. A further step in the NMS research could aggregate such overlapping or similar verbal concepts into groups, to avoid the very low frequencies of some variables observed in our study.

As explained, all patients in our study were on the old FGAs prior to developing NMS. It would be of clinical interest to generate similar de-identified files of archival data for suspected NMS in patients treated with second generation antipsychotics (SGAs), also known as atypical antipsychotics. Establishing symptom frequency profiles, comparable to our Table III, but for SGAs including clozapine would help to avoid the pitfalls of overzealous reductionism in diagnosing NMS cases.

In general, SGAs have been associated with a lower incidence of NMS with milder severity of symptoms [2]. Muscle rigidity and hyperthermia may not occur in these cases making it difficult to diagnose someone without these classic symptoms. Unfortunately, if not diagnosed promptly, these cases may be fatal. Hopefully identifying symptom patterns and frequencies by using statistical analyses of archival data will broaden our outlook and lead to diagnostic sophistication and clinically appropriate treatment responses.

A similar NMS symptom profile derived from archival data on milder NMS cases could enhance our understanding of this syndrome in a spectrum perspective. This will lead to earlier diagnosis and clinical management that is stage specific and optimal.

Unfortunately, patients suspected of being in the throes of NMS are often only identified when they reach the severe stage of the syndrome. Usually, only case studies have been published with a review of the syndrome [17]. However, with closer surveillance, perhaps a survey study could be conducted to determine which medications were given at different stages of NMS and with what outcomes.

\section{CONCLUSIONS}

Rigidity, tachycardia, elevated blood pressure, and autonomic instability were the most frequent symptoms reported in $>65 \%$ of patients, i.e., more than two-thirds of the suspected 212 NMS cases. Higher level of temperature correlated significantly only with tachycardia $(\mathrm{r}=0.28$, $\mathrm{p}=0.001$, 2-tailed) and with more cases of coma $(\mathrm{r}=0.18$, $\mathrm{p}=0.001,2$-tailed).

It is important to generate similar de-identified files of archival data for suspected cases of NMS in patients treated with SGAs and to establish tabular data of their symptom frequencies as done in the present study for the FGAs. It would also be valuable to generate similar data of symptom frequencies on milder or prodromal cases of NMS in order to facilitate earlier diagnosis and optimal, stage specific clinical management of NMS.

\section{ACKNOWLEDGEMENT}

Sadly, Dr Cernovsky passed away shortly after the submission of this article. His contributions to the advancement of knowledge in mental health were outstanding. We dedicate this article to his memory.

\section{REFERENCES}

[1] American Psychiatric Association. Diagnostic and Statistical Manual of Mental Disorders. Fifth Edition. DSM-5. Washington, DC: American Psychiatric Publishing, 2013.

[2] Caroff SN, Mann SN, Sullivan KA, Campbell EC: Neuroleptic malignant syndrome. Movement Disorder Emergencies: diagnosis and treatment. Humana Press, Inc. (in press).

[3] Belvederi M, Guaglianone A, Bugliani M, Calcagno P, Respino M, Serafini G, et al. Second-generation antipsychotics and neuroleptic malignant syndrome: systematic review and case report analysis. Drugs RD. 2015; 15(1): 45-62.

[4] Caroff SN, Mann SC, Campbell EC. Atypical antipsychotics and neuroleptic malignant syndrome. Psychiatric Annals. 2000; 30: 314321.

[5] Mann SC, Caroff SN, Keck, PE, Lazarus A. Neuroleptic Malignant Syndrome and related Conditions. $2^{\text {nd }}$ edition. Washington, DC: American Psychiatric Publishing, 2003.

[6] Uvais NA. Atypical neuroleptic malignant syndrome (NMS). Asian Journal of Psychiatry. 2017; 30; 120-121.

[7] Picard LS, Lindsay S, Strawn JR, Kaneria R, Patel NC, Keck Jr. PE. Atypical neuroleptic malignant syndrome: diagnostic controversies and considerations. Pharmacotherapy. 2008; 28: 530-535.

[8] Velamoor VR, Norman RM, Caroff SN, Mann SC, Sullivan KA, Antelo E. Progression of symptoms in neuroleptic malignant syndrome. Journal of Nervous and Mental Disease. 1994; 182(3): 168173.

[9] Velamoor R. Neuroleptic malignant syndrome. A neuro-psychiatric emergency: recognition, prevention, and management. Asian Journal of Psychiatry. 2017; 29: 106-109. 
[10] Cheshire Jr. WP. Thermoregulatory disorders and illness related to heat and cold stress. Autonomic Neuroscience: Basic and Clinical. 2016; 196: 91-104.

[11] Mackowiak PA, Wasserman SS, Levine MM. A critical appraisal of $98.6^{\circ} \mathrm{F}$, the upper limit of the normal body temperature, and other legacies of carl reinhold august wunderlich. JAMA. 1992; 268(12): 1578-1580.

[12] Geneva II, Cuzzo B, Fazili T, Javaid W. Normal Body Temperature: A Systematic Review. Open Forum Infectious Diseases. 2019.

[13] Woodbury MM, Woodbury MA. Neuroleptic-induced catatonia as a stage in the progression toward neuroleptic malignant syndrome. Journal of the American Academy of Child and Adolescent Psychiatry. 1992; 31: 1161-1164.

[14] Velamoor VR, Swamy GN, Parmar RS, Williamson P, Caroff SN. Management of suspected neuroleptic malignant syndrome. Canadian Journal of Psychiatry. 1995; 40(9): 545-550.

[15] Strawn JR, Keck PE, Caroff SN. Neuroleptic Malignant Syndrome. American Journal of Psychiatry. 2007; 164(6): 870-876.

[16] Velamoor V, Cernovsky Z. Age and Gender Specific Patterns of the Neuroleptic Malignant Syndrome. Archives of Psychiatry and Behavioral Sciences. 2019; 2(2): 22-26.

[17] Velamoor VR. Neuroleptic malignant syndrome: Recognition, prevention, and management. Drug Safety. 1998; 19(1): 73-82.

V. R. Velamoor graduated in Medicine from Osmania University in India and received his training in Psychiatry in the United Kingdom. He is currently Professor of Psychiatry at the Northern Ontario School of Medicine as well as Professor Emeritus at the Western University School of Medicine. He was previously on Faculty at Cornell University. Professor Velamoor has published over a hundred scientific articles as well as book chapters and psychiatric monographs in the areas of suicidal behaviour, violence, stress at the workplace, collaborative care, geriatric psychopharmacology and the Neuroleptic Malignant Syndrome (NMS). His work in NMS is internationally recognized and frequently cited. He has received Fellowships from the Royal College of Psychiatrists, UK, as well as the American Psychiatric Association.

S. C. Mann received his medical degree from the Sidney Kimmel Medical College of Thomas Jefferson University where he also completed his residency in psychiatry. He worked for the United States Veterans Health Administration for over thirty years and retired as Chief of Mental Health \& Behavioral Sciences at the Louisville VA Medical Center, Louisville, KY. $\mathrm{He}$ is currently in private practice. Dr. Mann has previously held faculty positions as Professor of Psychiatry at both the University of Pennsylvania School of Medicine and the University of Louisville School of Medicine. He is a Distinguished Life Fellow of the American Psychiatric Association and is certified by the American Board of Psychiatry and Neurology. He has published over one hundred scientific publications including three books. Dr. Mann's main research focus includes neuroleptic malignant syndrome, malignant catatonia, tardive dyskinesia, and the neurobiology of schizophrenia.

M. A. Woodbury graduated in Medicine from University of Puerto Rico School of Medicine. Dr. Woodbury is the professor of psychiatry at the University of Puerto Rico in San Juan, Puerto Rico, USA.

Z. Z. Cernovsky is the professor of psychiatry in the medical school of Western University, London, Ontario, Canada. Dr. Cernovsky has published more than 200 scientific articles in the field of psychiatry and medical psychology, and also chapters in university textbooks. 